\title{
miR-30b-5p inhibits proliferation, invasion, and migration of papillary thyroid cancer by targeting GALNT7 via the EGFR/PI3K/AKT pathway
}

Ye Wang ${ }^{1,2}$, Congjun Wang ${ }^{1,2}$, Zhao Fu $^{1,2}$, Siwen Zhang ${ }^{1,2}$ and Junqiang Chen ${ }^{1,2^{*}}$ (1)

\begin{abstract}
Background: Papillary thyroid carcinoma (PTC) is a common endocrine tumor. Increasing evidence has shown that microRNA dysfunction is involved in the occurrence and development of cancer. The expression of MicroRNA-30b-5p (miR-30b-5p) was down-regulated in PTC; however, its role in the development of PTC is not clear. Hence, this study aimed to explore the role and mechanism of miR-30b-5p in the occurrence and development of PTC.

Methods: The qRT-PCR assay was used to detect the expression of miR-30b-5p in 60 cases of papillary thyroid carcinoma along with their matched non-cancerous tissues. This study explored the biological function of miR-30b-5p by the functional gain and loss experiments in vitro and vivo. The direct target gene of miR-30b-5p and its signaling pathway was identified through bioinformatics analysis, qRT-PCR, western blot, rescue experiments, and double luciferase 3'-UTR report analysis.

Results: This study demonstrated that the low expression of miR-30b-5p is related to poor clinicopathological features. Functionally, the overexpression of miR-30b-5p inhibited the proliferation, invasion, and migration of PTC cells. Bioinformatics and luciferase analysis showed that GALNT7 is the direct and functional target of miR-30b-5p. Moreover, miR-30b-5p inhibited the proliferation of PTC in vivo by inhibiting the expression of GALNT7. The studies on the mechanism have shown that GALNT7 promotes cell proliferation and invasion by activating EGFR/PI3K/AKT kinase pathway, which can be attenuated by the kinase inhibitors.
\end{abstract}

Conclusions: Overall, miR-30b-5p inhibited the progression of papillary thyroid carcinoma by targeting GALNT7 and inhibiting the EGFR/PI3K/AKT pathway.

Keywords: Papillary thyroid carcinoma, miR-30b-5p, GALNT7, The EGFR/PI3K/AKT pathway, Progression

\footnotetext{
${ }^{*}$ Correspondence: chenjunqiang@gxmu.edu.cn

${ }^{2}$ Guangxi Medical University, Guangxi Key Laboratory of Enhanced

Recovery after Surgery for Gastrointestinal Cancer, Nanning 530021, Guangxi, China

Full list of author information is available at the end of the article
}

\section{Background}

Thyroid cancer is a common endocrine malignancy, and its incidence has shown a rapid increase in recent decades [1]. Differentiated thyroid cancer (DTC) accounts for more than $90 \%$ of all thyroid cancers, including the papillary, follicular, and poorly differentiated histological subtypes [2]. Although most patients diagnosed with DTC have a good prognosis, a significant proportion of patients have persistent or recurrent disease, with a original author(s) and the source, provide a link to the Creative Commons licence, and indicate if changes were made. The images or other third party material in this article are included in the article's Creative Commons licence, unless indicated otherwise in a credit line to the material. If material is not included in the article's Creative Commons licence and your intended use is not permitted by statutory regulation or exceeds the permitted use, you will need to obtain permission directly from the copyright holder. To view a copy of this licence, visit http://creativecommons.org/licenses/by/4.0/. The Creative Commons Public Domain Dedication waiver (http://creativeco mmons.org/publicdomain/zero/1.0/) applies to the data made available in this article, unless otherwise stated in a credit line to the data. 
minority reporting death [3]. Its occurrence and development seem as complex as a network system, and its underlying mechanism is still largely unknown. Thus, it is critical to explore the underlying molecular mechanisms and identify the potential therapeutic targets in papillary thyroid carcinoma (PTC).

Mature microRNAs (miRNAs) belong to a class of evolutionally conserved, single-stranded, small (approximately 19-23 nucleotides), endogenously expressed, and non-protein-coding RNAs that act as post-transcriptional regulators of gene expression in a wide variety of animals, plants, and viruses [4]. Numerous studies have documented the role of miRNA in cancer progression [5], and several miRNAs have been reported to be associated with thyroid carcinomas [6-10]. Overexpression of miR-146b-5p and miR-146b-3p is associated with PTC metastasis [9]. MiR-139-5p can significantly reduce the migration and proliferation of anaplastic thyroid cancer cells [6]. MiR-125a-5p exerts its tumor inhibitory effect by directly inhibiting the expression of CD147 protein in thyroid cancer [7]. MiR-222 promotes the invasion and metastasis of thyroid cancer by targeting PPP2R2A [8]. Additionally, the miR-30b-5p is reported as a new diagnostic marker to improve the diagnosis of PTC [11]. MiR-30b-5p often acts as a tumor suppressor, inhibiting the proliferation and metastasis of cancer, including renal cell carcinoma [12], lung cancer [13], and colorectal cancer [14]. In terms of mechanism, miR-30b-5p is reported to control tumor or disease progression by regulating autophagy [15-18], epithelial-mesenchymal transition (EMT) $[12,19]$, and mTOR signaling pathway [20]. However, the role of miR-30b-5p in PTC is not very clear.

Overexpression of epidermal growth factor receptor (EGFR) is associated with thyroid carcinoma progression [21]. Recent studies have found that the detection of EGFR expression in patients with PTC is helpful to judge the prognosis of patients with PTC [22-25]. In addition, EGF/EGFR signal pathway plays a crucial role in the EMT progression of thyroid cancer cells [26, 27]. EGFR is activated by its ligand epidermal growth factor (EGF), which triggers a signal cascade, resulting in enhanced migration and invasion of thyroid cancer cells [28]. There is no doubt that the expression level of EGFR is also regulated by miRNA. MiR-146b blocks the EGFR pathway to inhibit the progression of ovarian cancer [29]. MiR-137 inhibits growth and invasion by targeting EGFR in thyroid cancer cells [30]. MiR-7 affects the progress of PTC by regulating the expression of EGFR [31]. However, the relationship between MiR-30b-5p and EGFR is not clear.

Our results showed that the expression of miR-30b-5p in PTC was significantly lower than that of the paracancerous tissues. MiR-30b-5p plays the role of the tumor suppressor gene by directly inhibiting the expression of Polypeptide $N$-Acetylgalactosaminyltransferase 7(GALNT7). The abnormal expression of GALNT7 and its family members is related to the occurrence and development of many kinds of malignant tumors [3240]. Therefore, we focused on the interaction between MiR-30b-5p and GALNT7 in PTC cells. We report a new regulatory pathway composed of MiR-30b-5p/GALNT7/ EGFR, which provides potential biomarkers and therapeutic targets for the diagnosis and treatment of PTC.

\section{Methods}

\section{Patients and samples}

The PTC and non-tumor tissues were collected from 60 PTC patients admitted to the first affiliate Hospital of Guangxi Medical University in the past year (Additional file 2: Table S1). They were initially diagnosed with PTC and received PTC lobectomy. Tumor tissues were immediately collected, and the non-tumor tissues were sampled more than $5 \mathrm{~cm}$ away from the tumor border. The samples were stored using an RNA protective reagent (RNA isolater Total RNA Extraction Reagent, R40101 , Vazyme) at $-80{ }^{\circ} \mathrm{C}$. None of these patients received any chemotherapy or radiotherapy before the operation. This study and its informed consent were reviewed and certified by the Ethics Committee of the first affiliated Medical College of Guangxi Medical University [2015 (KY-E-018)].

\section{Cell culture and transfection}

PTC cell lines TPC-1, KTC-1, and B-CPAP were purchased from Wuhan Pu-nuo-sai Life Technology Co. Ltd. (Wuhan, China). K-1 was purchased from Shanghai Gene Chemical Technology Co., Ltd. Normal thyroid epithelial cell line, namely, Nthy-ori-3-1, were purchased from Shanghai Zhongqiao Xinzhou Biotechnology Co., Ltd. Cells were recently authenticated by STR profiling. Cells are routinely tested for mycoplasma prior to experimentation (MycoAlert Detection Kit (\#LT07-418, Lonza). All cell lines were cultured in RPMI 1640 with $10 \%$ fetal bovine serum (FBS, Gibco-BRI, USA) and incubated at $37{ }^{\circ} \mathrm{C}$ with $5 \% \mathrm{CO}_{2}$. Cells were digested using $0.25 \%$ trypsin and EDTA. MiR-30b-5p (agomir, mimics, and inhibitor), NC (Negative Control-agomir, -mimics, and -inhibitor), si-GALNT7, and si-NC were designed by Guangzhou Ribobio Co., Ltd. GALNT7 overexpressed plasmids and corresponding negative control groups were constructed by Shanghai Genechemical Technology Co., Ltd. The transfection was performed when cell confluency reached approximately $80-90 \%$. The miRNA mimic, miRNA inhibitor, small interference RNAs(siRNAs), and plasmids were transfected using Lipofectamine 3000 transfection reagent (Invitrogen) according to the manufacturer's protocol. The culture 
medium was replaced $8 \mathrm{~h}$ post-transfection. Subsequent experiments were carried out after $48 \mathrm{~h}$.

\section{Western blotting}

Total protein was extracted by the lysis method using RIPA and 1\% PMSF for $30 \mathrm{~min}$ at $4{ }^{\circ} \mathrm{C}$ and then centrifuged at $12,000 \mathrm{rpm}$ for $15 \mathrm{~min}$ at $4{ }^{\circ} \mathrm{C}$. The supernatant liquid was transferred to another EP tube and boiled in $5 \times$ SDS loading buffer at $95{ }^{\circ} \mathrm{C}$ for $5 \mathrm{~min}$. Before boiling, the concentration of the total protein was estimated by the BCA assay. The amount of the loaded protein per lane was $30 \mu \mathrm{g}$. The proteins were electrophoresed in 10\% SDS-PAGE gels and transferred to PVDF membranes. The membranes were incubated with $5 \%$ bovine serum albumin (BSA) in TBST for $1 \mathrm{~h}$ at room temperature and then incubated overnight at $4{ }^{\circ} \mathrm{C}$ with the primary antibodies. The following day, membranes were incubated with secondary antibody for $1 \mathrm{~h}$. Finally, the proteins were detected by incubating the membranes with a chemiluminescent substrate (Pierce ${ }^{\mathrm{TM}}$ ECL Western Blotting Substrate, Thermo Scientific, \# 32106) and were exposed subsequently to the FlourchemE Imaging System. The used primary antibodies and inhibitors are listed as follows: GALNT7 rabbit Polyclonal Antibody (Thermo Fisher Scientific, \# PA5-64163, 1:1000); E-cadherin rabbit Polyclonal antibody (Proteintech, \#20874-1AP, 1:10,000); Vimentin mouse Monoclonal antibody (Proteintech, \#60330-1-Ig, 1:20,000); SNAI1 rabbit Polyclonal antibody (Proteintech, \#13099-1-AP, 1:500); EGFR Rabbit Monoclonal antibody (Abcam, \# ab52894, 1:1000); PI3K Rabbit Monoclonal antibody (CST, \#4249, 1:1000); Phospho-PI3K p85 (Tyr458)/p55 (Tyr199) antibody (CST, \#4228, 1:1000); AKT rabbit Polyclonal antibody (Proteintech, \#10176-2-AP, 1:1000); Phospho-AKT (Ser473) mouse Monoclonal antibody (Proteintech, \#66444-1-Ig, 1:2000); GAPDH mouse Monoclonal antibody (Proteintech, \#60004-1-Ig, 1:10,000); BMS-599626 (AC480) (Abcam, \#ab142063): BMS-599626 was diluted in DMSO (10uM) and added after $24 \mathrm{~h}$ of cell culture (the volume of DMSO was less than 1\%). The follow-up experiment was carried out after $72 \mathrm{~h}$ of culture.

\section{Real-time quantitative PCR}

RNA samples from the frozen thyroid tissue specimens and cultured cells were extracted using the FastPure ${ }^{\circledR}$ Cell/Tissue Total RNA Isolation Kit V2 (Vazyme, Nanjing, China). The concentration and purification of RNA were detected by the Nanodrop 2000 Spectrophotometer (Thermo Scientific, USA). The concentration was above $1000 \mathrm{ng} / \mathrm{ul}$, and A260/A280 ratio was between 1.8 and 2.0. The cDNA was generated according to the manufacturer's instructions (Vazyme HiScript III RT SuperMix for qPCR (+ gDNA wiper), Cat\# R323-01and
Takara Mir-X miRNA First-Strand Synthesis Kit, Cat\# 63813). The resulting cDNA was used in real-time PCR detection, which was performed by the 7500 real-time PCR system (Applied Biosystems, Waltham, MA, USA) using the ChamQTM Universal SYBR ${ }^{\circledR}$ qPCR Master Mix and miRNA Universal SYBR qPCR Master Mix (Vazyme). The qPCR conditions were set according to the manufacturer's instructions (The conditions for the qPCR were shown in S1). All the primers were synthesized by Takara Biotechnology Co., Ltd. (Takara, China). MiR-30b-5p and GALNT7 expression was calculated as $2^{\wedge}(-\Delta \Delta C T)$, which was normalized using U6 and GAPDH expression, respectively. Primers used were as follows: GALNT7 forward: 5'-TCCTCGGTAACTTTGAAC CCA-3', GALNT7 reverse: 5'-GCGGTCCAGTGAGAT CATGTC-3; miR-30b-5p forward: 5'-CCGAAACATCCT ACACTCAGCTAA -3', miR-30b-5p reverse: 5'-CAG TGCGTGTCGTGGAGT-3'; U6 forward: 5'-CTCGCT TCGGCAGCACA -3', U6 reverse: 5'-AACGCTTCA CGAATTTGCGT -3'; GAPDH forward: 5'-TGTGGG CATCAATGG ATTTGG -3', GAPDH reverse: 5'-ACA CCATGTATTCCGGGTCAAT - $3^{\prime}$

\section{Analysis of THCA data and prediction of downstream target genes of miRNA}

The TCGA (The Cancer Genome Atlas) data of 573 patients with thyroid carcinoma were downloaded from the TCGA-GDC website (https://portal.gdc.cancer.gov, last accessed March 20, 2021). The enrichment analysis of the GO (Gene Ontology) and KEGG (Kyoto Encyclopedia of Genes and Genomes) pathway was performed using the GSEA software (Gene set enrichment analysis, GSEA v. 4.0). The differential expression of mir-30b-5p was tested using the package limma. TargetScan (http:// www.targetscan.org), miRDB (http://mirdb.org/miRDB), miRmap (https://mirmap.ezlab.org/), PITA (http:// genie.weizmann.ac.il/pubs/mir07/mir07_data.html), and miRanda (http://www.microrna.org) websites were used to explore the downstream targets of miR-30b-5p.

\section{CCK-8 assay and EdU incorporation assay}

Cell proliferation was monitored using the CCK-8 kit (Dojindo, USA). A day before transfection, cells were seeded into 96-well culture plates at a density of $2 \times 10^{3}$ cells/well. The number of proliferating cells was determined by the absorbance measured at $450 \mathrm{~nm}$ using a microplate reader (96-well microplate, Corning) at 0, 24, 48, and $72 \mathrm{~h}$. All experiments were repeated thrice. The EdU incorporation assay was performed using a BeyoClick $^{\mathrm{TM}}$ EdU cell proliferation kit with Alexa Fluor 567 (RiboBio, Guangzhou, China). The treated PTC cells were cultured in 96-well plates for $24 \mathrm{~h}$. Then, $100 \mu \mathrm{L}$ of $50 \mu \mathrm{M}$ EdU culture medium was added to each well and 
incubated for $2 \mathrm{~h}$. Each well was further incubated with $4 \%$ polyformaldehyde at room temperature for $30 \mathrm{~min}$. Later, 1X Apollo and DAPI staining reagents were added sequentially and incubated at room temperature in a decolorizing shaker for $30 \mathrm{~min}$. The images were captured using an Olympus IX81 inverted fluorescent microscope and CellSens software (Olympus Corporation). All experiments were repeated thrice.

\section{Wound-healing assay}

The treated cells (K-1 and B-CPAP) were seeded into 6-well plates for overnight culture. Before scratching, the cells were starved for $24 \mathrm{~h}$ in a medium containing $0 \%$ fetal bovine serum (FBS). A wound of similar size was introduced into a monolayer with a $200 \mu \mathrm{L}$ pipette tip. Wounded monolayer cells were washed thrice with PBS to remove cell debris and then cultured further. After $24 \mathrm{~h}$, the speed of wound closure was monitored and photographed. All the experiments were performed in triplicates.

\section{Transwell assay}

Transwell invasion and migration assay was performed using $8.0 \mu \mathrm{m}$ Transwell Permeable Support (Corning). The transfected PTC cells were cultured in serum-free RPMI 1640 medium for $24 \mathrm{~h}$ at $37{ }^{\circ} \mathrm{C}$ and then suspended in the same medium. The cells were condensed to $3 \times 10^{4}$ cells in $200 \mu \mathrm{L}$ cell suspension and then added to the upper chamber for migration test or Matrigel-coated upper chamber for invasion experiment. The RPMI 1640 medium with $10 \%$ FBS was added to the bottom chamber. After $24 \mathrm{~h}$ of incubation, the filter membrane was fixed with $90 \%$ ethanol and stained with crystal violet. For visualization, five random areas of each chamber were counted using an inverted microscope (Olympus Corporation).

\section{Flow cytometry CFSE assay}

For apoptosis assay, the Annexin V-FITC/PI apoptosis kit (MULTI SCIENCES, Hangzhou, China) was used, and the procedure was followed as per the manufacturer's protocols. Firstly, cells (K-1 and B-CPAP) were harvested and washed twice using pre-cold PBS buffer. Then, $5 \mu \mathrm{L}$ of PI Staining Solution and $5 \mu \mathrm{L}$ of Annexin V-FITC were added to each sample, and cells were incubated for $10 \mathrm{~min}$. BD FACSVerse flow cytometer was used to measure the cell apoptosis. The data of the cell cycle and apoptosis assay were analyzed by BD FlowJo ${ }^{\mathrm{TM}} \mathrm{v} 10.7$.

\section{Luciferase reporter assay}

The wild-type GALNT7 or mut-GALNT7 fragment was constructed and inserted downstream of the pmiRRB-Report $^{\mathrm{TM}}$ (Ribobio, China) luciferase reporter gene.
$293 \mathrm{~T}$ cells were transfected with $50 \mathrm{ng}$ of reporter construct and $50 \mathrm{nM}$ of miRNA mimic per well using Lipofectamine 3000 (Invitrogen, \# L3000-015). The culture medium was changed $6 \mathrm{~h}$ after transfection. After $48 \mathrm{~h}$, the cells were lysed using the passive lytic buffer (Promega, \#E1910), and the reporter gene expression was detected by the dual-luciferase reporter analysis system (Promega, \#E1910). All transfection experiments were performed in triplicates.

Immunohistochemistry (IHC) and immunofluorescence (IF) Thyroid cancer tissue was fixed with $10 \%$ formalin, and then the paraffin-embedded sections were treated with specific primary antibodies. After incubating overnight at $4{ }^{\circ} \mathrm{C}$, the slices were washed twice and further incubated with SignalStain ${ }^{\circledR}$ Boost IHC detection reagent (CST, \# 8114) at room temperature. Then, slices were labeled using SignalStain DAB substrate kit (CST, \#8059) and observed under an inverted microscope (Olympus Corporation). The experiment was repeated at least thrice. For IF analysis, the cell climbing slices were incubated overnight with anti-E-cadherin and anti-vimentin antibodies at $4{ }^{\circ} \mathrm{C}$. After three washing steps in PBS, cells were incubated in secondary antibodies with respective fluorophores: goat anti-mouse Alexa fluor 555 (Beyotime, China) and goat anti-rabbit Alexa fluor 488 (Beyotime, China). Fluorescence was assessed using an SP8 Leica Confocal Microscope.

\section{Nude xenograft mice model}

Thirty BALB/c female nude mice, aged between 4 and 6 weeks, were purchased from the Institute of Experimental Animals of Guangxi Medical University and randomly divided into the NC agomir and miR-30b-5p agomir groups. B-CPAP cells were injected into the right axilla of mice at a concentration of $5 \times 10^{7}$ cells $/ \mathrm{mL}(200$ $\mu \mathrm{L} /$ mouse). After 3 weeks, the intratumoral injection of $100 \mathrm{nM}$ miRNA agomir was administered in the mice every 4 days for 2 weeks. Every 4 days, tumour xenograft growth was measured with calipers, and volume was calculated according to the following formula: tumor volume $\left(\mathrm{Mm}^{3}\right)=(\text { length } \times \text { width })^{2} \times 0.5$. After 40 days, the nude mice were euthanized by overdose sodium pentobarbital at $300 \mathrm{mg} / \mathrm{kg}$, and the tumor tissues were taken for immunohistochemistry and western blot assays. These animal experiments were approved by the Ethical Committee for Animal Utilization and Protection of Guangxi Medical University $(202007052,2020)$.

\section{Statistical analyses}

All data (three biological repeats or samples) were expressed as the mean \pm standard deviation (SD). SPSS 20.0 software (IBM, Chicago, IL, USA) and GraphPad 
Prism 7.0 (GraphPad Software Inc., CA, USA) was used for statistical analysis. T-test and one-way ANOVA were used for comparison between the groups. $\mathrm{P}<0.0001$ is indicated as ${ }^{* * * * *} \mathrm{P}<0.001$ as ${ }^{* * *} \mathrm{P}<0.01$ as $*$, and $\mathrm{P}<0.05$ as *. All the experiments were repeated thrice.

\section{Results}

MiR-30b-5p is down-regulated in PTC and is related to poor clinical features

The analysis of the THCA dataset from the TCGA database shows that the expression of mir-30b-5p is low in PTC (Fig. 1A). To further verify this result, the qRT-PCR assay was used to evaluate the expression of mir-30b-5p in 60 pairs of PTC and paracancerous tissues. The results showed that the expression level of mir-30b-5p in PTC was lower than that of the paracancerous tissues (Fig. 1B; Additional file 1). 60 tumor tissues were divided into high expression and low expression groups to explore the correlation between the expression level of mir-30b-5p and clinicopathological features (Additional file 2: Table S1). It was found that the expression of mir-30b-5p was significantly correlated with the $\mathrm{T}$ stage (T1vs.T2, $\mathrm{P}=0.0047$; T1vs.T3, $\mathrm{P}<0.0001$ ), lymph node metastasis (N0 vs. $\mathrm{N} 1, \mathrm{P}<0.0001$ ), and tumor stage (I vs. II, $\mathrm{P}=0.0214$ ) (Fig. 1C-E). Also, we detected the expression of mir30b-5p in normal thyroid cells (Nthy-ori-3-1) and four PTC cells (TPC-1, KTC-1, K-1, and B-CPAP). The results showed that compared to the normal thyroid cells, the expression level of mir-30b-5p in $\mathrm{K}-1$ and B-CPAP cells was down-regulated (Fig. 1F, $\mathrm{P}=0.0232$ and $\mathrm{P}<0.0001$; Additional file 1) while the expression level of mir-30b-5p in TPC-1 and KTC-1 cells was upregulated (Fig. 1F, $\mathrm{P}<0.0001$ and $\mathrm{P}<0.0001$; Additional file 1). Therefore, $\mathrm{K}-1$ and B-CPAP cell lines were used for all the subsequent studies, and the results suggested that the down-regulation of mir-30b-5p may be related to the development of PTC.

\section{Mir-30b-5p inhibits proliferation and causes apoptosis of PTC cells in vitro}

Mir-30b-5p mimic was transfected into K-1 and B-CPAP cells, respectively. Significant overexpression of miR30b-5p in K-1 and B-CPAP cells was verified using qRTPCR (Fig. 2A, $\mathrm{P}=0.0002$ and $\mathrm{P}=0.0006$; Additional file $1)$. We first investigated the effects of overexpression of mir-30b-5p on PTC cell proliferation. Following the miR-30b-5p overexpression, the proliferative capability of PTC cell lines was investigated using the CCK8 assay (Fig. 2B; Additional file 3) and EdU staining (Fig. 2C, $\mathrm{E}, \mathrm{P}=0.0026$, and $\mathrm{P}=0.0020$; Additional file 4), which showed a decrease in the proliferation. Moreover, the number of apoptotic cells in the miR-30b-5p mimic group was found to be significantly more than that of the NC mimic group (Fig. 2D, F, $\mathrm{P}<0.0001$ and $\mathrm{P}=0.0007$ ). These results suggested that the miR-30b-5p regulated the proliferation and apoptosis of PTC cells.

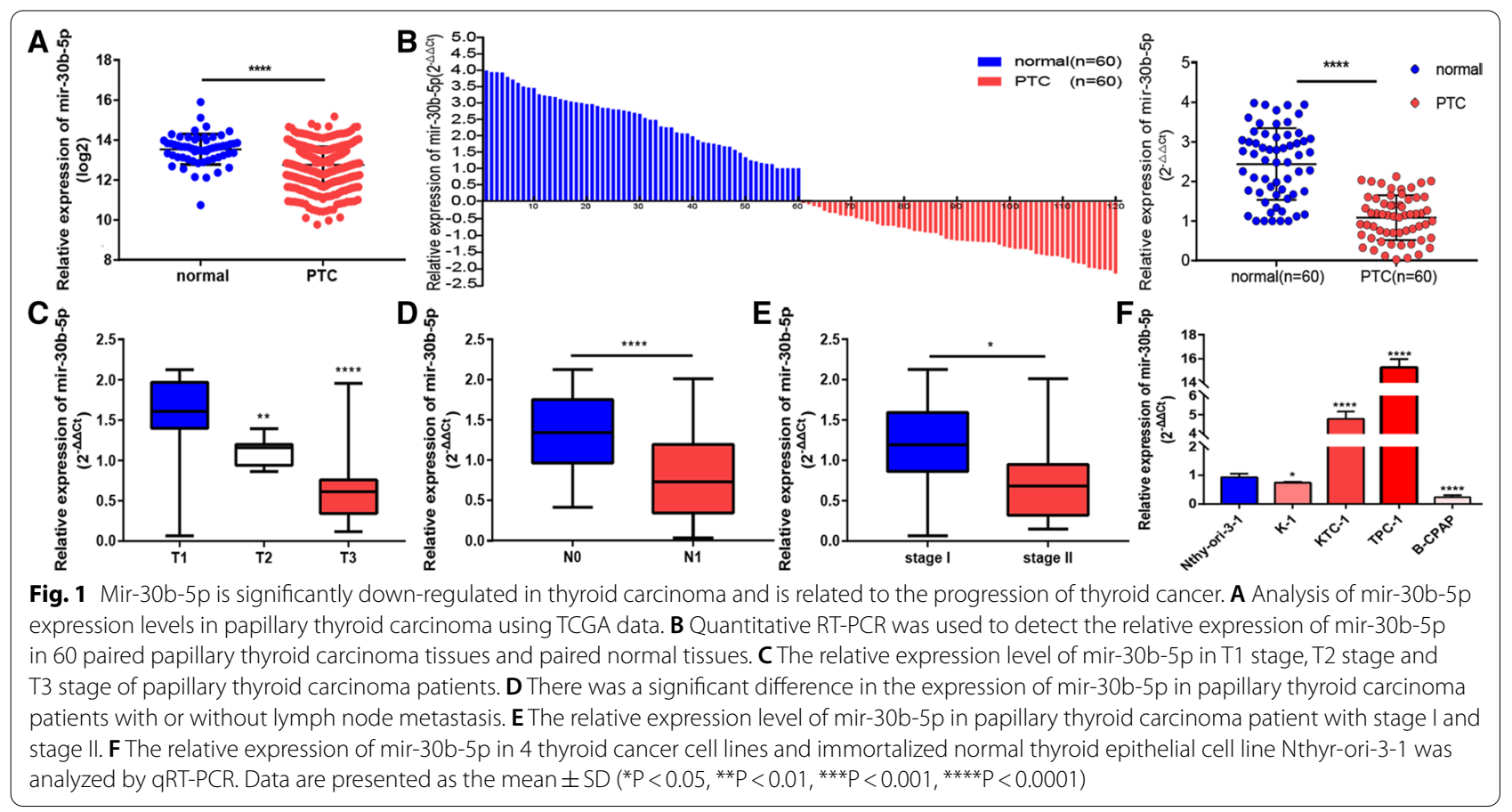




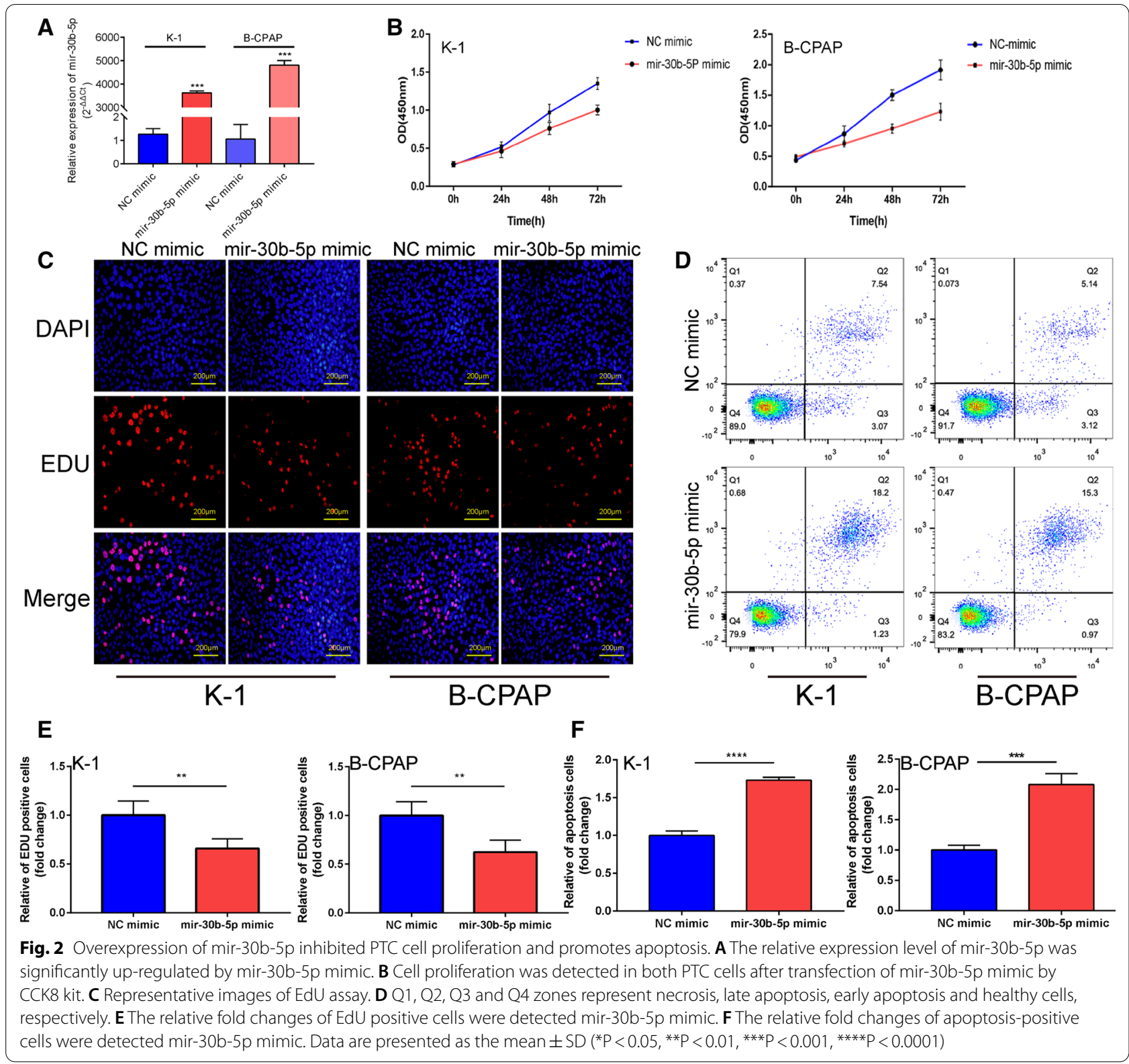

Mir-30b-5p suppresses migration and invasion of the PTC cells in vitro

To further analyze the biological behavior of mir30b-5p in PTC, the migratory and invasive ability of PTC cells were measured using the wound healing and transwell assays. Wound healing assays showed that the overexpression of miR-30b-5p notably inhibited the PTC cell migration (Fig. 3A, B; P $=0.0013$ and $\mathrm{P}=0.0011)$. Transwell migration and invasion assays also indicated that miR-30b-5p markedly decreased the number of migrated and invaded cells in $\mathrm{K}-1$ and B-CPAP cell lines (Fig. 3C-E, $\mathrm{P}<0.0001$; Additional file 5). It is generally believed that EMT is the key process in tumor migration, invasion, metastasis, and spread. Thus, we tested whether miR-30b-5p is involved in EMT (Epithelial-mesenchymal transition). For the protein expression of EMT markers, western blotting was used to verify the representative EMT markers (E-cadherin, snail, and vimentin). The results showed that the overexpression of mir-30b-5p decreased the expression of mesenchymal markers, including snail and vimentin while increasing the expression of epithelial marker E-cadherin (Fig. 3F; Additional file 6). The changes in the EMT markers, namely, E-cadherin and Vimentin, were further confirmed by the IF analysis. These data suggested that the overexpression of 


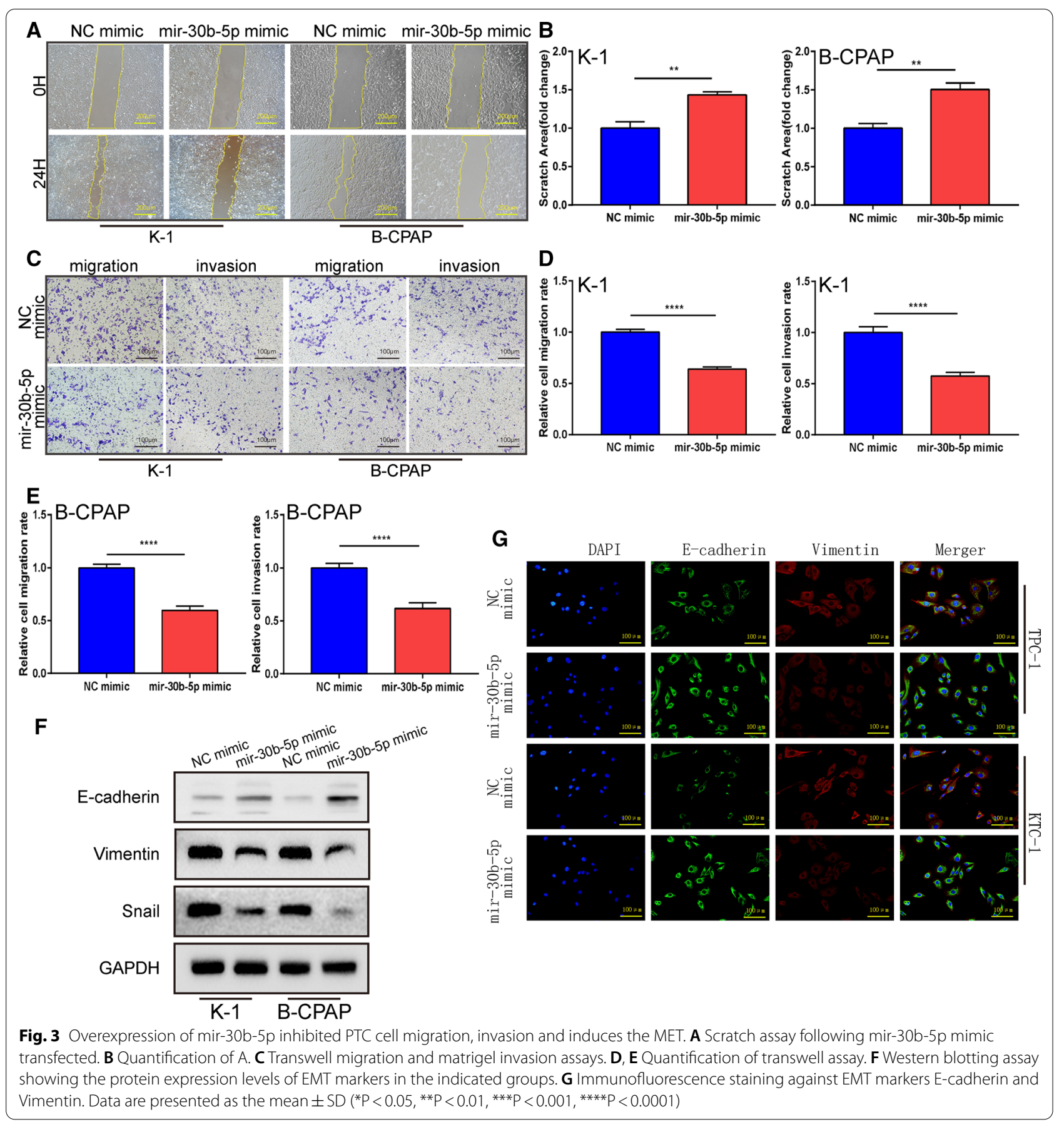

miR-30b-5p can effectively inhibit the metastatic characteristics of PTC cells.

\section{MiR-30b-5p directly targets GALNT7}

To clarify the potential mechanism underlying the miR30b-5p function, we used TargetScan, miRDB, miRmap, PITA, and miRanda websites to explore the downstream targets of miR-30b-5p. The gene sets were selected based on their overlapping with the upregulated genes in the TCGA-THCA tumor samples for subsequent studies, with the Venn diagram showing a total of two genes being included (Fig. 4A). Here, we chose the target gene GALNT7 for a follow-up study. Subsequently, PTC cell lines were transfected with both the miR-30b-5p mimic and miR-30b-5p inhibitor. After $24 \mathrm{~h}$, the qRT-PCR assay was used to detect the expression levels of GALNT7. 


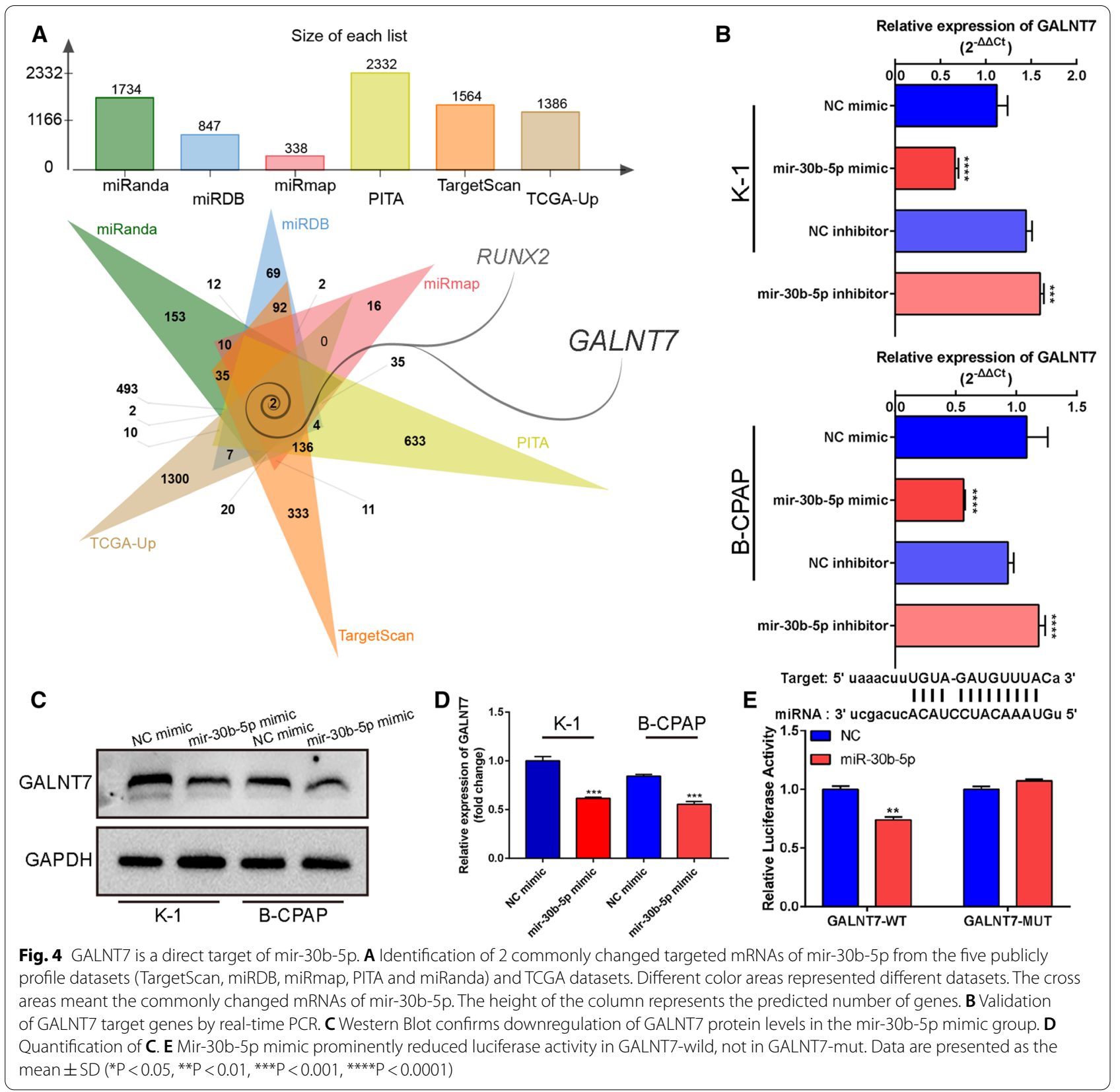

The results showed that the expression of GALNT7 was found to be lower in the mir-30b-5p mimic group compared to that of the NC mimic group, while we obtained opposite results in the miR-30b-5p inhibitor and $\mathrm{NC}$ inhibitor groups (Fig. $4 \mathrm{~B}, \mathrm{P}<0.0001, \mathrm{P}=0.0007$, $\mathrm{P}<0.0001$ and $\mathrm{P}<0.0001$; Additional file 1). This result was also confirmed by western blot assay, which showed that the level of GALNT7 protein decreased significantly after the overexpression of mir-30b-5p in K-1 and B-CPAP cell lines (Fig. 4C, D; $\mathrm{P}=0.0001$ and $\mathrm{P}=0.0001$; Additional file 6). These results suggested that GALNT7 may be a potential target for miR-30b-5p. To confirm that GALNT7 is the direct target of miR-30b-5p, we designed a luciferase reporter gene with wild type (Wt) or mutant (Mut) 3'-UTR in the GALNT7 gene. Luciferase reporter gene analysis showed that the relative luciferase activity in the miR-30b-5p and GALNT7-WT cotransfected cells was significantly lower than that of the control group (Fig. 4E, $\mathrm{P}=0.0032$; The detailed site mutation information is in Additional file 7). This luciferase activity is canceled once a mutation occurs at a potential miR-30b-5p binding site. These results showed that the 
GALNT7 is the direct target of miR-30b-5p, and the expression of GALNT7 in PTC cells is negatively regulated by miR-30b-5p.

\section{GALNT7 overexpression rescues the aggressive characteristics of PTC cells inhibited by miR-30b-5p}

To verify that GALNT7 is the functional target of miR30b-5p, we carried out rescue experiments in the PTC cells. The overexpression plasmid was transferred into the PTC cell lines, where the negative control group was the vector group along with the GALNT7 overexpression group and the GALNT7 group. The qRTPCR and western blot assays were used to verify the transfection efficiency, and the results are shown in Fig. 5A $(P=0.0012$ and $\mathrm{P}=0.0002$; Additional file 1$)$ and $\mathrm{B}(\mathrm{P}=0.0003$ and $\mathrm{P}=0.0058$; Additional file 6$)$. When miR-30-5p mimic was transfected into $\mathrm{K}-1$ and B-CPAP cells, a decrease was observed in the mRNA and protein levels of GALNT7 while the co-transfection of pcDNA-GALNT7 and miR-30b-5p mimics restored the mRNA and protein levels of GALNT7 (Fig. 5C, $\mathrm{P}=0.0167, \mathrm{P}=0.0084, \mathrm{P}=0.0327$, and $\mathrm{P}=0.0013$; Additional file 1) (Fig. $5 \mathrm{D}, \mathrm{E}, \mathrm{P}=0.0021$, $\mathrm{P}=0.0022, \quad \mathrm{P}=0.0064$, and $\mathrm{P}=0.005 ;$ Additional file 6). Although miR-30b-5p inhibits the proliferation, invasion, and migration of PTC cells, GALNT7 recurrence can rescue the changes in the process. EdU staining showed that the transfection of pcDNAGALNT7 could antagonize the decrease of cell proliferation induced by miR-30b-5p mimics (Fig. 5F, $\mathrm{G}, \mathrm{P}=0.0369, \mathrm{P}=0.0042, \mathrm{P}=0.0154$ and $\mathrm{P}=0.0031$ Additional file 4). Transwell invasion and migration assay results suggested that the transfection of miR30b-5p mimic weakens the metastatic ability of PTC cells while the co-transfection of pcDNA-GALNT7 and miR-30b-5p mimic can reverse this effect (Fig. $5 \mathrm{H}$, $\mathrm{I}, \mathrm{P}=0.0011, \mathrm{P}=0.0006, \mathrm{P}=0.0018$, and $\mathrm{P}=0.0005$; Additional file 5). The results of quantifications are shown in Fig. 5J $(\mathrm{P}=0.0016, \mathrm{P}=0.0004, \mathrm{P}=0.0028$, and $\mathrm{P}=0.0002)$. Overall, these results indicated that GALNT7 is a functional target of miR-30b-5p, which inhibits the malignant behavior of PTC cells by downregulating GALNT7.

\section{Knockdown of GALNT7 suppresses the aggressive characteristics of PTC cells}

GALNT7 is a member of the glycosyltransferase family, the disorder of which has been found in many diseases [33, 36, 41-44]. The results from the TCGA database suggest that GALNT7 is highly expressed in PTC (Additional file 12). We used the siRNA to silence the expression of GALNT7 and observed whether knocking down GALNT7 showed the same function as miR-30b-5p. As shown in Fig. 6A-C, the mRNA and protein levels of GALNT7 decreased significantly after the transfection of si-GALNT7 (Additional files 1 and 6). This si-GALNT7-2 was then selected for subsequent experiments. EdU staining showed that the proliferation of $\mathrm{K}-1$ and B-CPAP cells was significantly inhibited after silencing GALNT7 (Fig. 6D, $\mathrm{P}=0.0035$ and $\mathrm{P}=0.0037$; Additional file 4). The invasion and migration experiments showed that the number of migration and invasion of the cells decreased significantly in GALNT7 knocked-out PTC cells (Fig. 6E-G, $\mathrm{P}=0.0020, \mathrm{P}=0.0005, \mathrm{P}=0.0003$, and $\mathrm{P}=0.0035$; Additional file 5). Also, the downregulation of GALNT7 caused more apoptosis of tumor cells (Fig. 6H, $\mathrm{I}, \mathrm{P}<0.0001$ and $\mathrm{P}=0.0006$ ). These results suggested that the knockout of the GALNT7 gene showed consistency with the overexpression of miR-30b-5p.

\section{GALNT7 promotes cell proliferation and invasion by activating EGFR/PI3K/AKT pathway}

Using the TCGA transcriptome data, we performed the GSEA analysis on the signaling pathways that GALNT7 might have been involved in. The results suggested that the EGFR-related signaling pathways were significantly enriched (Fig. 7A and B; Detailed data in Additional file 9). Therefore, we detected the activity of the EGFR/ PI3K/AKT pathway in K-1 and B-CPAP cells and used selective HER1 and HER2 inhibitors (BMS-599626, $10 \mu \mathrm{M})$ to inhibit the activity of the pathway. As shown in Fig. $7 \mathrm{C}$ and $\mathrm{E}$, the levels of major signaling molecules were significantly lower in the EGFR/PI3K/AKT pathway in the PTC cells treated with BMS -599626 or siGALNT7-2 than those found in the negative control group (Additional file 6). Similarly, the expression levels of EGFR, p-PI3K, and p-AKT were higher in PTC cells transfected with pcDNA-GALNT7 than those observed

(See figure on next page.)

Fig. 5 Mir-30b-5p regulates proliferation and metastasis by targeting GALNT7. A Quantitative RT-PCR was used to detect the relative expression of GALNT7 after cells transfected with empty vector or pcDNA-GALNT7. B The protein levels of GALNT7 were detected after transfection with empty vector or pcDNA-GALNT7. Right panel, quantification of the result. C-E K-1 and B-CPAP cells were transfected with NC-mimic, miR-30b-5p mimic, or cotransfected with miR-30b-5p mimic and Vector, miR-30b-5p mimic and pcDNA-GALNT7.The mRNA and protein levels of GALNT7 were detected using qRT-PCR and western blot, respectively. F EdU was used to detect cell proliferation after transfection of NC-mimic, miR-30b-5p mimic or co-transfection of miR-125a-5p mimic and Vector, miR-125a-5p mimic and pcDNA-GALNT7. G Quantification of F. H Cell migration and invasion were detected using the Transwell assay after transfection with NC-mimic, miR-30b-5p mimic or co-transfection with miR-125a-5p mimic and Vector, miR-125a-5p mimic and pcDNA-GALNT7. I, and $\mathbf{J}$ Quantification of $\mathbf{H}$. Data are presented as the $m e a n \pm S D\left({ }^{*} P<0.05,{ }^{* * P}<0.01,{ }^{* *} P<0.001\right.$, ****P $<0.0001$ ) 

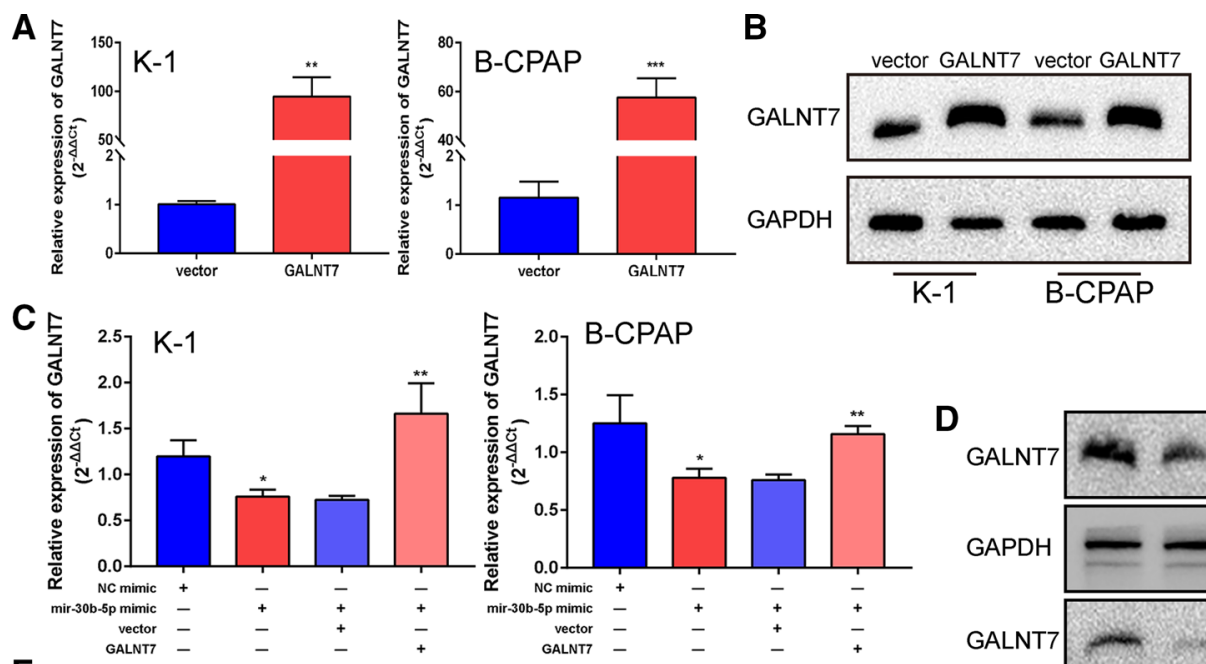

E
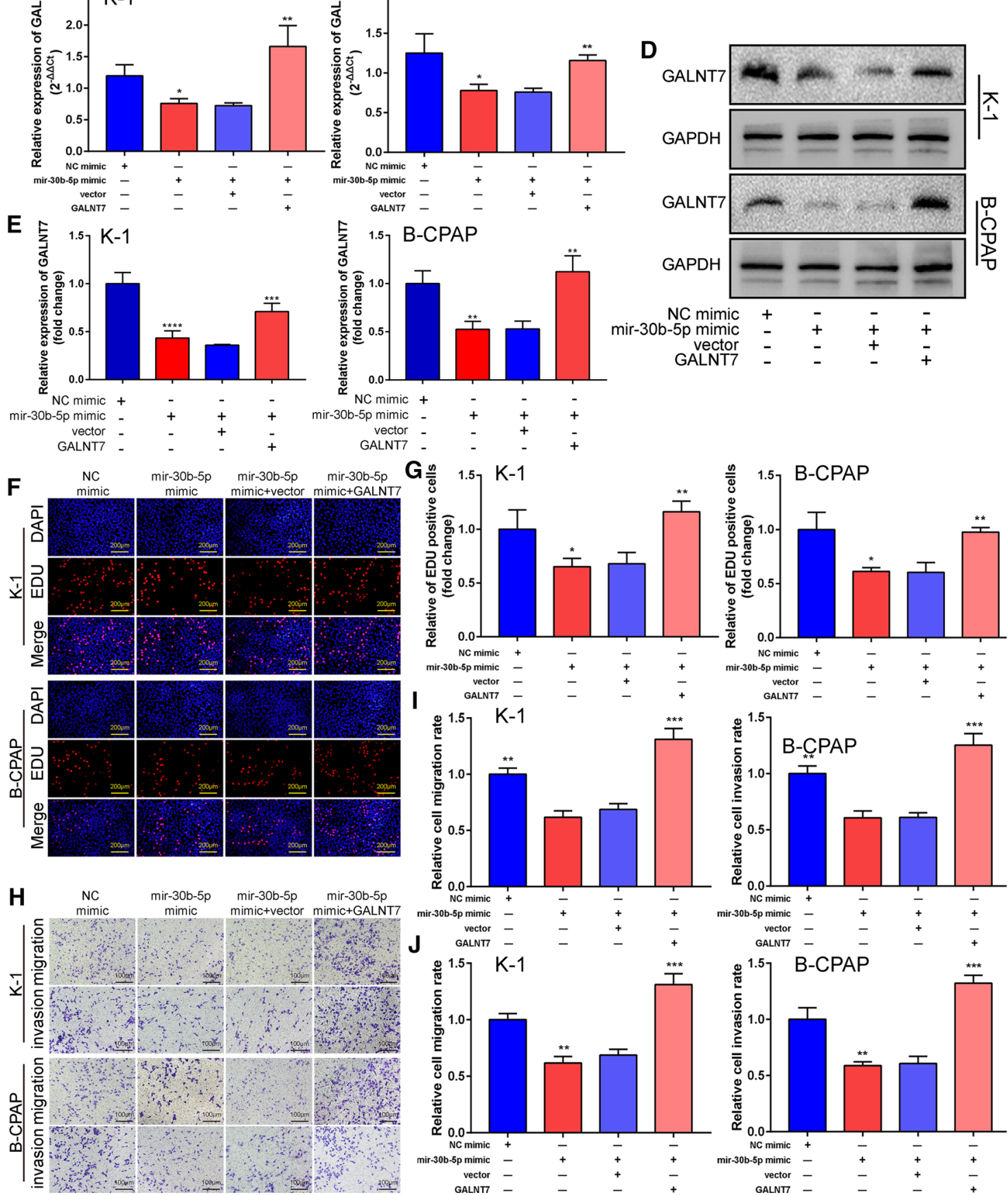

Fig. 5 (See legend on previous page.) 


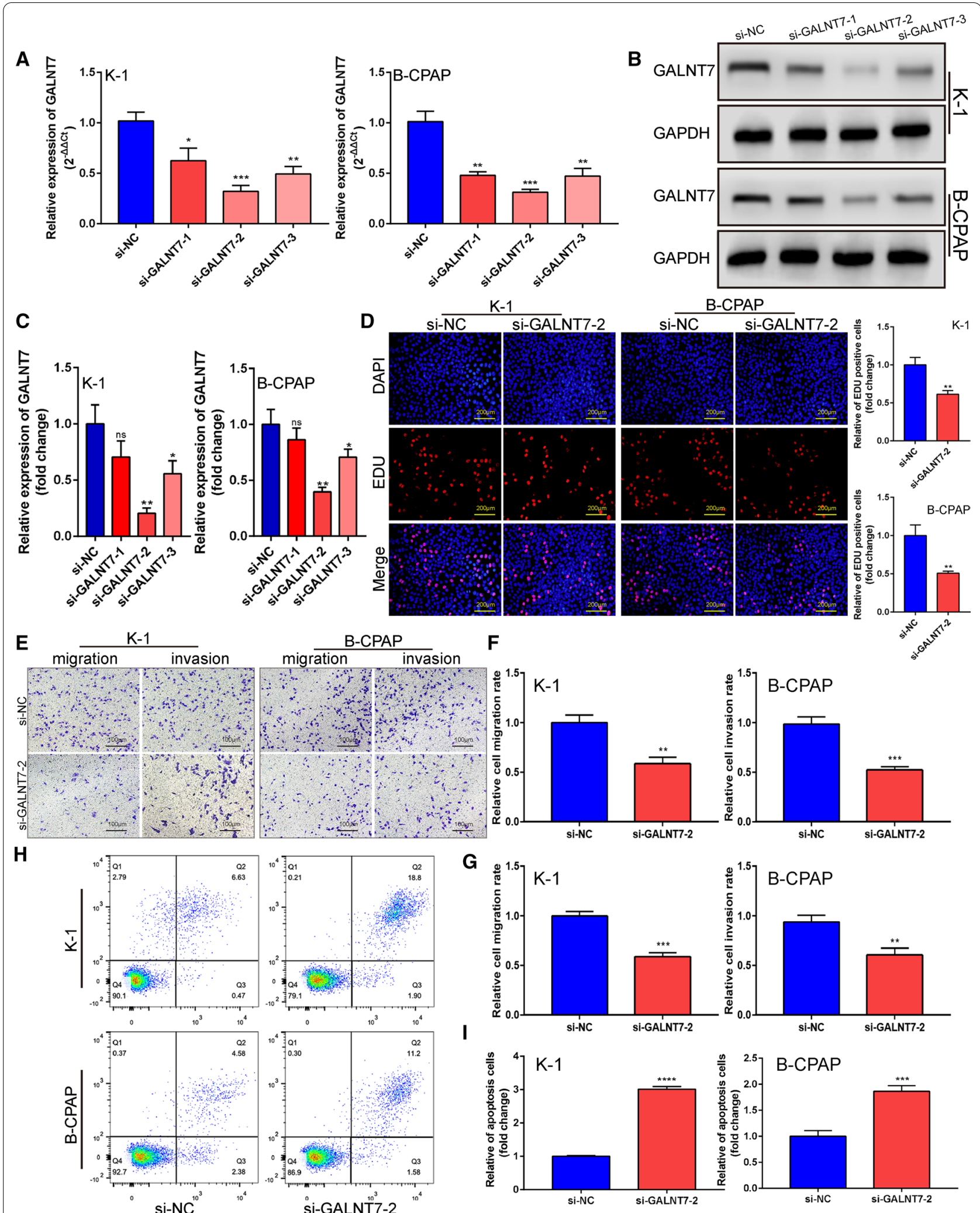

Fig. 6 Down-regulation of GALNT7 inhibited PTC cell proliferation and promotes apoptosis. A, B qRT-PCR and western blot assays were used to verify the silencing effect of siRNA. C Quantification of B. D The effect of silencing GALNT7 on cell proliferation was detected by EdU. Right panel, quantification of the result. E Transwell migration and matrigel invasion assays. F, G Quantification of E. H Apoptosis assay. I The relative fold changes of apoptosis-positive cells were detected. Data are presented as the mean $\pm \mathrm{SD}\left({ }^{*} \mathrm{P}<0.05,{ }^{* *} \mathrm{P}<0.01,{ }^{* * *} \mathrm{P}<0.001,{ }^{* * *} \mathrm{P}<0.0001\right)$ 


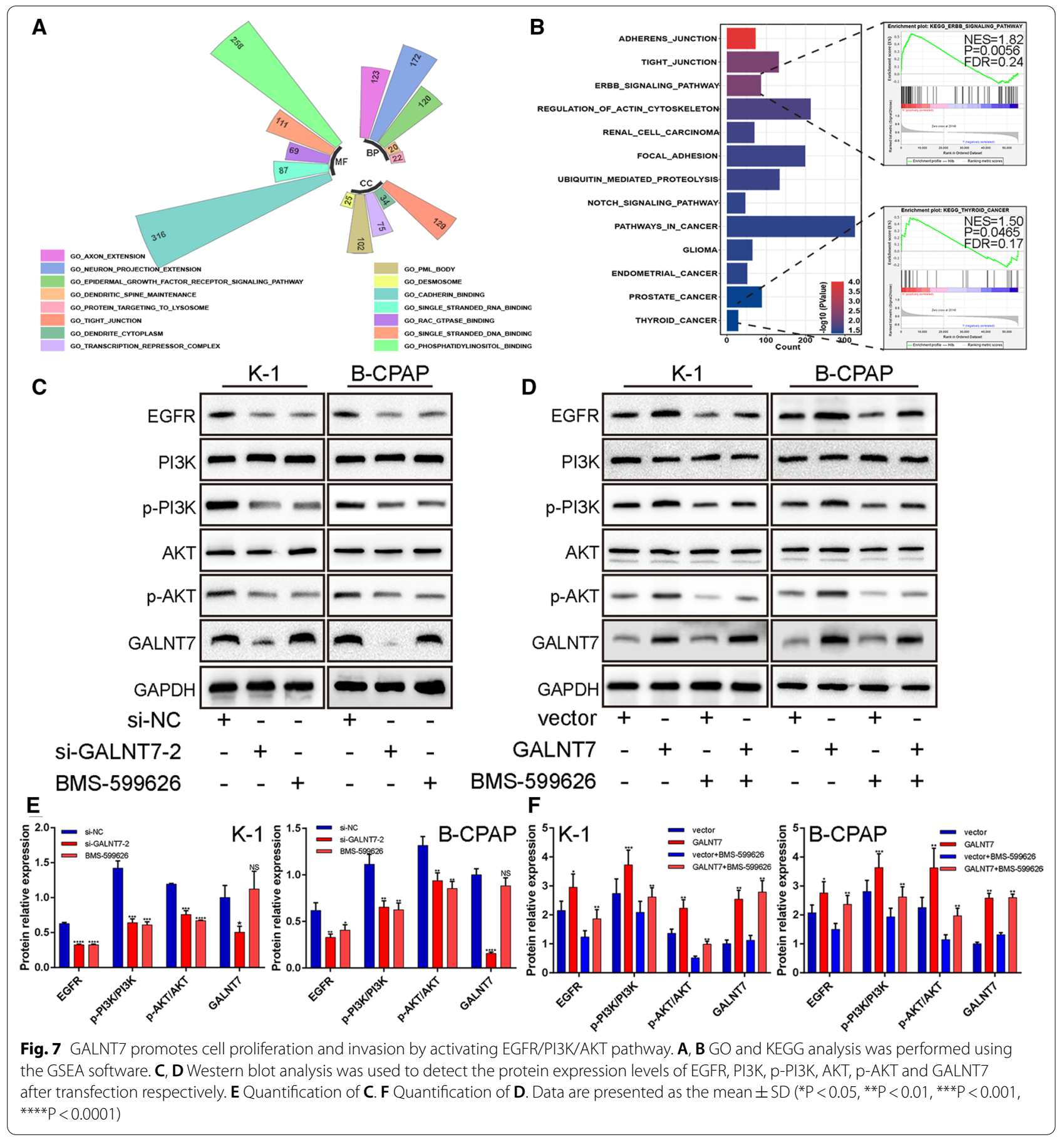

in the control group. After the pathway was blocked by BMS-599626, the expression of EGFR, p-PI3K, p-AKT in the GALNT7 group did not show any further increase. These results are shown in Figs. 7D and F (Additional file 6). Accordingly, the inhibition of the
EGFR/PI3K/AKT signaling pathway reduced the proliferation and invasion ability of the PTC cells (Fig. 8A-C; Additional files 4 and 5). Overall, these data suggested that the GALNT7 plays an important role in the progression of PTC through the EGFR/PI3K/AKT pathway. 


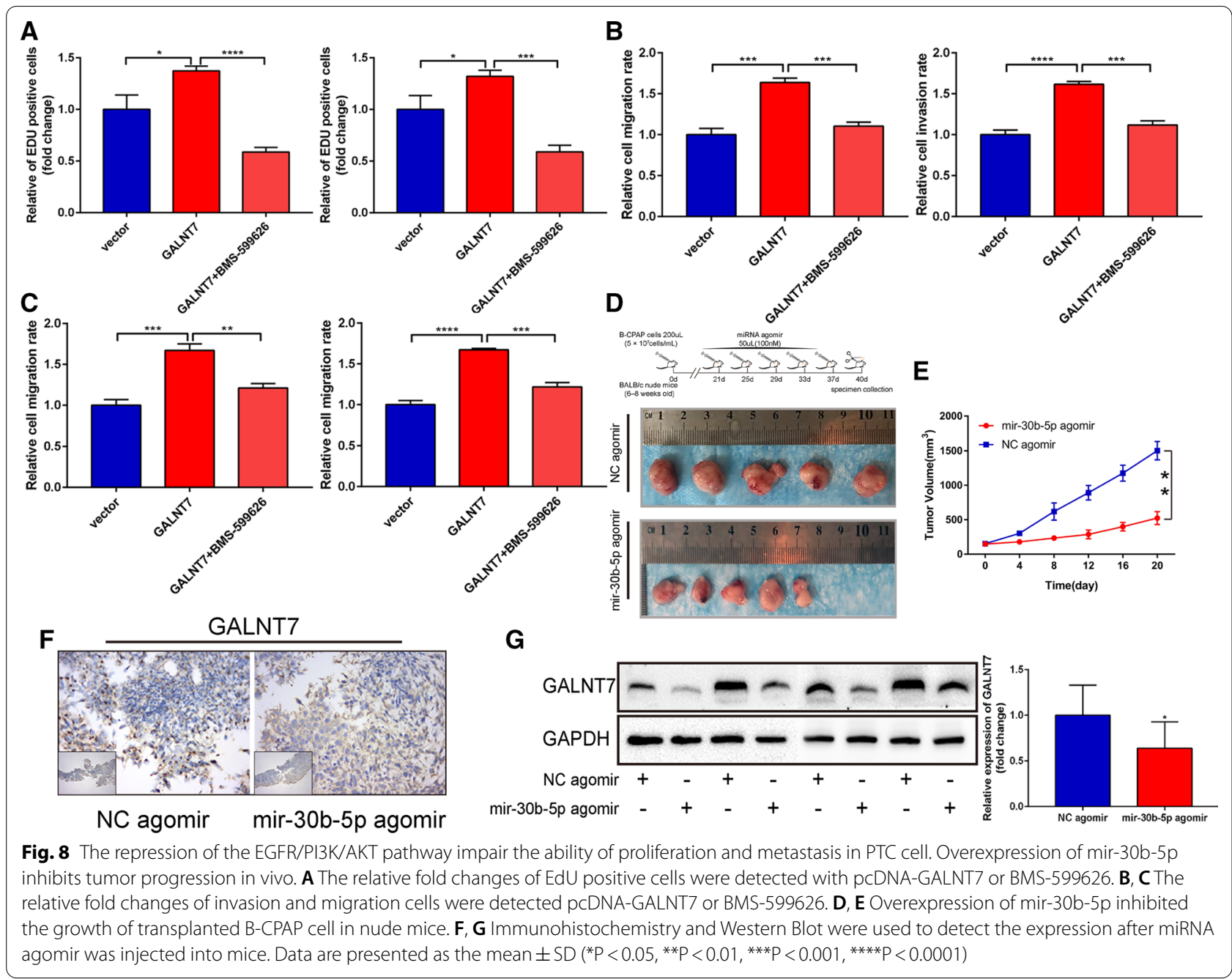

\section{Overexpression of miR-30b-5p suppressed the tumor} growth of PTC and the expression of GALNT7 in vivo

To study whether miR-30b-5p has an anti-tumor effect in vivo, we established a xenograft tumor model. The results showed that the tumor volume of the miR-30b-5p agomir group was significantly smaller than that of the control group and $\mathrm{NC}$ agomir group (Fig. 8D and E; $\mathrm{P}=0.0022$; Additional file 8). Additionally, compared to the NC agomir group, the protein expression of GALNT7 was found to be decreased in the mir-30b-5p agomir group (Fig. 8F and G; Additional file 6). These results suggested that miR-30b-5p may inhibit the growth of PTC in vivo by inhibiting the expression of GALNT7.

\section{Discussion}

MicroRNAs (miRNAs) are an important regulator of gene expression, and their disorder plays a vital role in cancer. Although few reports describe miRNA with carcinogenic function, it is generally agreed that miRNA deletion promotes tumorigenesis [45]. We included 60 pairs of PTC tissues and paired tissue samples in the clinical test to explore the expression pattern of miR-30b-5p and found that the expression of miR-30b-5p was downregulated in the PTC. The low expression of miR-30b-5p in PTC patients was positively correlated with the progression of the TNM stage. Interestingly, we found that miR-30b-5p was not always lowly expressed in thyroid cancer cell lines. The expression of miR-30b-5p in TPC-1 and KTC-1 was significantly higher than that in normal thyroid cell lines, K-1 and B-CPAP cell lines. Since both $\mathrm{K}-1$ and B-CPAP are braf mutant cell lines, we speculate that the abnormal result may be related to braf mutation. Subsequently, the results of TCGA-THCA data analysis supported our conjecture, which suggested that the expression of miR-30b-5p was lower in the population with braf mutations (Additional file 11; the difference was not statistically significant). These results suggest that the expression level of miR-30b-5p may be affected by braf 
mutation. It will be significant to verify the relationship between braf mutation and miR-30b-5p expression level in the future.

An increasing number of studies have indicated that most miRNAs regulate their target genes by repressing their expression levels [46]. As a tumor suppressor, miR$30 \mathrm{~b}-5 \mathrm{p}$ regulates the proliferation, metastasis, and EMT of renal cancer cells by down-regulating the expression of GNA13 [12]. In colon cancer, miR-30b-5p inhibits metastasis by targeting Rap1b [14]. MiR-30b-5p can inhibit the proliferation and cell cycle of hepatocellular carcinoma cell lines [47]. MiR-30b-5p inhibits the migration and invasion of esophageal cancer by targeting ITGA 5 and PDGFRb [48]. In addition, the miR-30b-5p inhibits lung cancer progression and enhances cisplatin sensitivity by targeting LRP8 [13]. This study shows that miR-30b-5p can significantly inhibit the proliferation, migration, and invasion of PTC cells while promoting the apoptosis of PTC cells. It is similar to the results of previous studies. Our results also suggest that GALNT7 is the downstream target gene of miR-30b-5p, which (Polypeptide $\mathrm{N}$-acetylgalactosaminyltransferase 7) is a member of the GalNAc-transferase family. The enzyme encoded by this gene controls the initiation step of mucin-type O-linked protein glycosylation, and it also controls the transfer of $\mathrm{N}$-acetylgalactosamine to serine and threonine amino acid residues [49]. Abnormal expression of GALNT7 has been found in many types of cancer, and MiR-125a-5p is shown to inhibit the formation of cervical cancer by inhibiting the expression of GALNT7 in vivo [36]. The high expression of GALNT7 is related to the poor prognosis of gliomas and can be used as an effective biomarker in gliomas [43]. The expression of GALNT7 in laryngeal carcinoma cells is negatively regulated by miR-34a and miR-34c, thus, playing a tumor inhibitory role [32]. SNHG7/miR-34a may be involved in the progression of colorectal cancer through the GALNT7 pathway [42]. The expression of GALNT7 in cervical cancer is often upregulated and promotes tumor proliferation [44]. Most importantly, experimental studies do not consistently support the role of GALNT7 in the tumor. The ectopic expression of miR-30b/30d has been reported to promote the metastasis of melanoma cells by directly targeting GALNT7 along with increasing the synthesis of immunosuppressive cytokine IL-10 while reducing the activation and recruitment of immune cells [50]. We evaluated the effect of GALNT7 on tumor behavior in PTC, and according to our experimental results, GALNT7 can promote the proliferation and metastasis of papillary thyroid cancer cell lines while silencing the expression of GALNT7 can promote the apoptosis of PTC cells. We believed that miR-30b-5p functioned through GALNT7, and to make this prediction convincing, we examined the expression of GALNT7 after down-regulation or overexpression of miR-30b-5p. The results of the rescue experiment showed that the inhibitory effect of miR-30b-5p on PTC cells could be neutralized by GALNT7. Also, we designed a luciferase experiment to confirm the targeted binding effect between mir-30b-5p/GALNT7. Convincingly, the constructed luciferase experiment proved that GALNT7 was the target of miR-30b-5p. These results confirmed that miR-30b-5p affects the progression of PTC cells by directly regulating GALNT7.

Previous reports have suggested that GALNT7 is involved in the regulation of tumor progression through PI3K/Akt/mTOR [42] and EGFR/PI3K/AKT [36] pathways. To determine the potential molecular mechanism of GALNT7 activity in PTC cells, we used bioinformatics to analyze the signaling pathways that GALNT7 might be involved in. The results showed that the EGFR-related signaling pathways were enriched many times, which was similar to the results of the previous studies. Many reports believe that the high expression of EGFR is positively correlated with the progress of PTC [22, 24, 25, 51, 52]. And the activation of the EGFR signal pathway contributes to the development of EMT in tumor cells [27, 28, 53]. Our research showed that GALNT7 positively regulated the EGFR/PI3K/AKT pathway, and the selective inhibitor BMS-599626 could weaken the promoting effect of GALNT7 on the proliferation and invasion capacity of PTC cells. When the inhibitors blocked the EGFR signal, it decreased the proliferation and invasiveness of PTC cells. GALNTs initiate the sequence by adding $\mathrm{N}$-acetylgalactosamine (GalNAc) to serine or threonine residues, resulting in a structure called TN polysaccharides. It has been reported that malignant tumors lead to a sharp increase in TN levels, and this phenotype is the same in most types of solid malignant tumors, with a frequency of 70-90\% [49, 54]. At present, the specific substrate of GALNT7 is not clear. Based on GSEA analysis, GALNT7 is involved in the modification of multiple small molecular, including cadherin binding, single-stranded RNA binding, Rac GTPase binding, single-stranded DNA binding, phosphatidylinositol binding, and Rho GTPase binding. In addition, the results of biological process enrichment analysis suggest that GALNT7 contributes to the transition from the G1 phase to the $\mathrm{S}$ phase in the mitotic cell cycle. These results may be the reason why GALNT7 increases the expression level of EGFR. The analysis result from TCGA datasets also provides strong evidence. The online analysis of GEPIA showed a significant positive correlation between the expression of GALNT7 and EGFR in TCGA-THCA datasets (This part of the data was shown in the Additional files 9, 10). These results suggest that GALNT7 up-regulates the expression of EGFR through a series 
of signal pathways. Of course, the modified substrate of GALNT7 is still worthy of further study. Anyway, this study shows that GALNT7 promotes the proliferation and metastasis of PTC cells by up-regulating the expression of EGFR and further activating the EGFR/PI3K/AKT pathway. However, there are still many shortcomings in this experiment. As mentioned earlier, the relationship between braf mutation and the expression level of miR-30b-5p needs to be verified, the modified substrate of GALNT7 needs to be identified, and how GALNT7 affects the process of cell cycle needs to be confirmed in the future.

\section{Conclusions}

This study confirmed for the first time that mir-30b-5p/ GALNT7 axis inhibits the proliferation and metastasis of PTC cells by regulating the EGFR/PI3K/AKT pathway, thus, providing a new target and better understanding of the possible pathogenesis. This result may help in designing molecular treatment strategies for PTC.

\section{Abbreviations}

PTC: Papillary thyroid carcinoma; TCGA: The Cancer Genome Atlas; mRNA: Messenger RNA; miRNA: MicroRNA; DTCs: Differentiated thyroid carcinoma; GSEA: Gene set enrichment analysis.

\section{Supplementary Information}

The online version contains supplementary material available at https://doi. org/10.1186/s12935-021-02323-X.

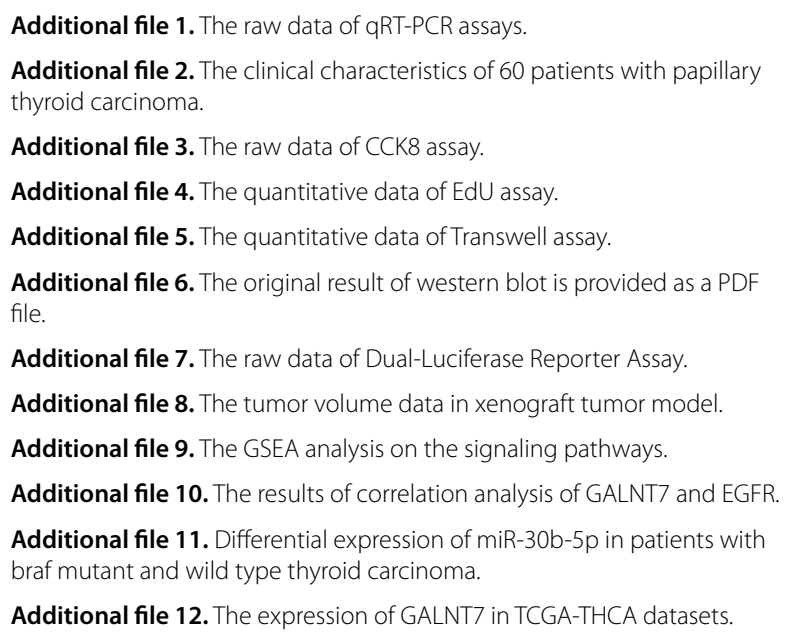

Additional file 2. The clinical characteristics of 60 patients with papillary thyroid carcinoma.

Additional file 3. The raw data of CCK8 assay.

Additional file 4. The quantitative data of EdU assay.

Additional file 5. The quantitative data of Transwell assay.

Additional file 6. The original result of western blot is provided as a PDF file.

Additional file 7. The raw data of Dual-Luciferase Reporter Assay.

Additional file 8. The tumor volume data in xenograft tumor model.

Additional file 9. The GSEA analysis on the signaling pathways.

Additional file 10. The results of correlation analysis of GALNT7 and EGFR.

Additional file 11. Differential expression of miR-30b-5p in patients with braf mutant and wild type thyroid carcinoma.

Additional file 12. The expression of GALNT7 in TCGA-THCA datasets.

\section{Acknowledgements}

The authors wish to acknowledge and thank Junqiang Chen for his valuable comments on our manuscript. The authors also thank all the staff and researchers who established and maintained The Cancer Genome Atlas.

\section{Authors' contributions}

Conceptualization: YW, CJW and JQC; methodology: YW and CJW; software: WY; validation; WY and CJW; resources: WY; data curation: WY; writing —original draft preparation:WY, ZF; writing — review and editing:WY, SWZ and JQC; visualization: WY; supervision: JQC; project administration: WY; funding acquisition: JQC. All authors read and approved the final manuscript.

\section{Funding}

This work was supported by the National Natural Science Foundation of China [grant no.82060430], the Guangxi Science and Technology Project [grant no.AD19245196], the Guangxi Key Research and Development Project [grant no.AB18126058] and the Guangxi Scientific Research and Technology Development Project [grant no.1598011-4].

\section{Availability of data and materials}

All data discussed are contained within the manuscript or the supporting material.

\section{Declarations}

Ethics approval and consent to participate

The study was conducted according to the guidelines of the Declaration of Helsinki and approved by the Ethics Committee of the first affiliated Medical College of Guangxi Medical University (protocol code KY-E-018, 2015) and the Ethical Committee for Animal Utilization and Protection of Guangxi Medical University $(202007052,2020)$.

\section{Consent for publication}

Not applicable.

\section{Competing interests}

The authors declare that they have no competing interests, and all authors should confirm its accuracy.

\section{Author details}

${ }^{1}$ The First Affiliated Hospital of Guangxi Medical University, Department of Gastrointestinal Gland Surgery, Nanning 530021, Guangxi, China. ${ }^{2}$ Guangxi Medical University, Guangxi Key Laboratory of Enhanced Recovery after Surgery for Gastrointestinal Cancer, Nanning 530021, Guangxi, China.

Received: 6 July 2021 Accepted: 9 November 2021 Published online: 24 November 2021

\section{References}

1. Shen X, Zhu G, Liu R, Viola D, Elisei R, Puxeddu E, et al. Patient ageassociated mortality risk is differentiated by BRAF V600E status in papillary thyroid cancer. J Clin Oncol. 2018;36(5):438-45.

2. Haugen B, Sherman S. Evolving approaches to patients with advanced differentiated thyroid cancer. Endocr Rev. 2013;34(3):439-55.

3. Valle L, Gorodeski Baskin R, Porter K, Sipos J, Khawaja R, Ringel M, et al. In thyroidectomized patients with thyroid cancer, a serum thyrotropin of $30 \mu \mathrm{U} / \mathrm{mL}$ after thyroxine withdrawal is not always adequate for detecting an elevated stimulated serum thyroglobulin. Thyroid. 2013;23(2):185-93.

4. Dong H, Lei J, Ding L, Wen Y, Ju H, Zhang X. MicroRNA: function, detection, and bioanalysis. Chem Rev. 2013;113(8):6207-33.

5. Prabhu K, Raza A, Karedath T, Raza S, Fathima H, Ahmed E, et al. Noncoding RNAs as regulators and markers for targeting of breast cancer and cancer stem cells. Cancers. 2020;12(2):351.

6. Montero-Conde C, Graña-Castro O, Martín-Serrano G, Martínez-Montes Á, Zarzuela E, Muñoz J, et al. Hsa-miR-139-5p is a prognostic thyroid cancer marker involved in HNRNPF-mediated alternative splicing. Int J Cancer. 2020;146(2):521-30.

7. Huang P, Mao L, Zhang Z, LvW, Feng X, Liao H, et al. Down-regulated miR-125a-5p promotes the reprogramming of glucose metabolism and cell malignancy by increasing levels of CD147 in thyroid cancer. Thyroid. 2018;28(5):613-23.

8. Huang Y, Yu S, Cao S, Yin Y, Hong S, Guan H, et al. MicroRNA-222 promotes invasion and metastasis of papillary thyroid cancer through targeting protein phosphatase 2 regulatory subunit b alpha expression. Thyroid. 2018;28(9):1162-73. 
9. Yu C, Zhang L, Luo D, Yan F, Liu J, Shao S, et al. NF2MicroRNA-146b-3p promotes cell metastasis by directly targeting in human papillary thyroid cancer. Thyroid. 2018;28(12):1627-41.

10. Chen L, Xiong L, Hong S, Li J, Huo Z, Li Y, et al. Circulating myeloid-derived suppressor cells facilitate invasion of thyroid cancer cells by repressing miR-486-3p. J Clin Endocrinol Metab. 2020;105(8):344.

11. Zhao Y, Liu X, Zhong L, He M, Chen S, Wang T, et al. The combined use of miRNAs and mRNAs as biomarkers for the diagnosis of papillary thyroid carcinoma. Int J Mol Med. 2015;36(4):1097-103.

12. Liu W, Li H, Wang Y, Zhao X, Guo Y, Jin J, et al. MiR-30b-5p functions as a tumor suppressor in cell proliferation, metastasis and epithelial-tomesenchymal transition by targeting G-protein subunit a-13 in renal cell carcinoma. Gene. 2017;626:275-81.

13. Qiu H, Shen X, Chen B, Chen T, Feng G, Chen S, et al. miR-30b-5p inhibits cancer progression and enhances cisplatin sensitivity in lung cancer through targeting LRP8. Apoptosis. 2021;26(5-6):261-76.

14. Fan M, Ma X, Wang F, Zhou Z, Zhang J, Zhou D, et al. MicroRNA-30b-5p functions as a metastasis suppressor in colorectal cancer by targeting Rap1b. Cancer Lett. 2020;477:144-56.

15. Li S, He J, Wang Z, Yu Y, Fu S, Zhang H, et al. miR-30b inhibits autophagy to alleviate hepatic ischemia-reperfusion injury via decreasing the Atg12Atg5 conjugate. World J Gastroenterol. 2016;22(18):4501-14.

16. Zhang L, Li J, Cui L, Shang J, Tian F, Wang R, et al. MicroRNA-30b promotes lipopolysaccharide-induced inflammatory injury and alleviates autophagy through JNK and NF-KB pathways in HK-2 cells. Biomed Pharmacother. 2018;101:842-51.

17. Guo H, Pu M, Tai Y, Chen Y, Lu H, Qiao J, et al. Nuclear miR-30b-5p suppresses TFEB-mediated lysosomal biogenesis and autophagy. Cell Death Differ. 2020;28(1):320-36.

18. Xi Z, Si J, Nan J. LncRNA MALAT1 potentiates autophagy-associated cisplatin resistance by regulating the microRNA-30b/autophagy-related gene 5 axis in gastric cancer. Int J Oncol. 2019;54(1):239-48.

19. Guan Y, Shi H, Xiao T. NUAK1 knockdown suppresses prostate cancer cell epithelial-mesenchymal transition, migration, and invasion through microRNA-30b-5p. Int J Clin Exp Pathol. 2018;11(12):5694-704.

20. Xu T, Qiu X, Sheng Z, Han Y, Wang J, Tian B, et al. Restoration of microRNA$30 \mathrm{~b}$ expression alleviates vascular calcification through the mTOR signaling pathway and autophagy. J Cell Physiol. 2019;234(8):14306-18.

21. Fisher K, Jani J, Fisher S, Foulks C, Hill C, Weber C, et al. Epidermal growth factor receptor overexpression is a marker for adverse pathologic features in papillary thyroid carcinoma. J Surg Res. 2013;185(1):217-24.

22. Tang C, Yang L, Wang N, Li L, Xu M, Chen G, et al. High expression of GPER1, EGFR and CXCR1 is associated with lymph node metastasis in papillary thyroid carcinoma. Int J Clin Exp Pathol. 2014;7(6):3213-23.

23. Lee $Y$, Lee J. Prognostic value of epidermal growth factor receptor, p53 and galectin-3 expression in papillary thyroid carcinoma. J Int Med Res. 2013;41(3):825-34.

24. Šelemetjev S, Bartolome A, Išić Denčić T, Đorić I, Paunović I, Tatić S, et al. Overexpression of epidermal growth factor receptor and its downstream effector, focal adhesion kinase, correlates with papillary thyroid carcinoma progression. Int J Exp Pathol. 2018;99(2):87-94.

25. IŠić Denčić T, Bartolome A, Šelemetjev S, Đorić I, Tatić S, Živaljević V, et al. High expression and localization of $\beta$-catenin and epidermal growth factor receptor identify high risk papillary thyroid carcinoma patients. Exp Mol Pathol. 2018;105(2):181-9.

26. Xue L, Su D, Li D, Gao W, Yuan R, Pang W. MiR-200 regulates epithelialmesenchymal transition in anaplastic thyroid cancer via EGF/EGFR signaling. Cell Biochem Biophys. 2015;72(1):185-90.

27. Zhao Y, Yuan B, Shen G. Mechanism of RET gene mediated EGFR signaling pathway on epithelial-mesenchymal transition, proliferation and apoptosis of papillary thyroid carcinoma cells. Eur Rev Med Pharmacol Sci. 2020;24(15):8036-47.

28. Zhang Z, Liu Z, Ren W, Ye X, Zhang Y. The miR-200 family regulates the epithelial-mesenchymal transition induced by EGF/EGFR in anaplastic thyroid cancer cells. Int J Mol Med. 2012;30(4):856-62.

29. Yan $M$, Han $M$, Yang $X$, Shen $R$, Wang $H$, Zhang $L$, et al. Dual inhibition of EGFR and IL-6-STAT3 signalling by miR-146b: a potential targeted therapy for epithelial ovarian cancer. J Enzyme Inhib Med Chem. 2021;36(1):1905-15.
30. Luo Y, Li X, Dong J, Sun W. microRNA-137 is downregulated in thyroid cancer and inhibits proliferation and invasion by targeting EGFR. Tumour Biol. 2016;37(6):7749-55.

31. Han J, Guo S, Wei N, Xue R, Li W, Dong G, et al. ciRS-7 promotes the proliferation and migration of papillary thyroid cancer by negatively regulating the miR-7/epidermal growth factor receptor axis. Biomed Res Int. 2020;2020:9875636

32. Li W, Ma H, Sun J. MicroRNA-34a/c function as tumor suppressors in Hep-2 laryngeal carcinoma cells and may reduce GALNT7 expression. Mol Med Rep. 2014;9(4):1293-8.

33. Niu J, Zhang L, Huang Y, Li C, Jiang N, Niu Y. MiR-154 inhibits the growth of laryngeal squamous cell carcinoma by targeting GALNT7. Biochem Cell Biol. 2018;96(6):752-60.

34. Kahai S, Lee S, Lee D, Yang J, Li M, Wang C, et al. MicroRNA miR-378 regulates nephronectin expression modulating osteoblast differentiation by targeting GalNT-7. PloS ONE. 2009;4(10):e7535.

35. Detarya M, Sawanyawisuth K, Aphivatanasiri C, Chuangchaiya S, Saranaruk $P$, Sukprasert $L$, et al. The O-GalNAcylating enzyme GALNT5 mediates carcinogenesis and progression of cholangiocarcinoma via activation of AKT/ERK signaling. Glycobiology. 2020;30(5):312-24.

36. Cao Q, Wang N, Ren L, Tian J, Yang S, Cheng H. miR-125a-5p posttranscriptionally suppresses GALNT7 to inhibit proliferation and invasion in cervical cancer cells via the EGFR/PI3K/AKT pathway. Cancer Cell Int. 2020;20:117.

37. Lin W, Yeh C. GALNT14: an emerging marker capable of predicting therapeutic outcomes in multiple cancers. Int J Mol Sci. 2020;21(4):1491.

38. Nakagawa Y, Nishikimi T, Kuwahara K, Fujishima A, Oka S, Tsutamoto T, et al. MiR30-GALNT1/2 axis-mediated glycosylation contributes to the increased secretion of inactive human prohormone for brain natriuretic peptide (proBNP) from failing hearts. J Am Heart Assoc. 2017;6(2):e003601.

39. Gaziel-Sovran A, Hernando E. miRNA-mediated GALNT modulation of invasion and immune suppression: a sweet deal for metastatic cells. Oncoimmunology. 2012;1(5):746-8.

40. Berois N, Gattolliat C, Barrios E, Capandeguy L, Douc-Rasy S, ValteauCouanet D, et al. GALNT9 gene expression is a prognostic marker in neuroblastoma patients. Clin Chem. 2013;59(1):225-33.

41. Wang J, Chen X, Han Z, Wang H, Wang Z, Li N, et al. Long non-coding RNA TP73-AS1 contributes to glioma tumorigenesis by sponging the miR-103a/GALNT7 pathway. Brain Res. 2020;1741:146886.

42. Li Y, Zeng C, Hu J, Pan Y, Shan Y, Liu B, et al. Long non-coding RNA-SNHG7 acts as a target of miR-34a to increase GALNT7 level and regulate PI3K Akt/mTOR pathway in colorectal cancer progression. J Hematol Oncol. 2018;11(1):89.

43. Hua S, Li H, Liu Y, Zhang J, Cheng Y, Dai C. High expression of GALNT7 promotes invasion and proliferation of glioma cells. Oncol Lett. 2018;16(5):6307-14.

44. Wu H, Chen J, Li D, Liu X, Li L, Wang K. MicroRNA-30e functions as a tumor suppressor in cervical carcinoma cells through targeting GALNT7. Transl Oncol. 2017;10(6):876-85

45. Lin S, Gregory RI. MicroRNA biogenesis pathways in cancer. Nat Rev Cancer. 2015;15(6):321-33.

46. Gao F, Kataoka M, Liu N, Liang T, Huang Z, Gu F, et al. Therapeutic role of miR-19a/19b in cardiac regeneration and protection from myocardial infarction. Nat Commun. 2019;10(1):1802.

47. Qin X, Chen J, Wu L, Liu Z. MiR-30b-5p acts as a tumor suppressor, repressing cell proliferation and cell cycle in human hepatocellular carcinoma. Biomed Pharmacother. 2017;89:742-50.

48. Xu J, Lv H, Zhang B, Xu F, Zhu H, Chen B, et al. miR-30b-5p acts as a tumor suppressor microRNA in esophageal squamous cell carcinoma. J Thorac Dis. 2019;11(7):3015-29.

49. Schjoldager K, Vakhrushev S, Kong Y, Steentoft C, Nudelman A, Pedersen $\mathrm{N}$, et al. Probing isoform-specific functions of polypeptide GalNAc-transferases using zinc finger nuclease glycoengineered simple cells. Proc Natl Acad Sci USA. 2012;109(25):9893-8.

50. Gaziel-Sovran A, Segura M, Di Micco R, Collins M, Hanniford D, VegaSaenz de Miera E, et al. miR-30b/30d regulation of GalNAc transferases enhances invasion and immunosuppression during metastasis. Cancer Cell. 2011;20(1):104-18. 
51. Dai Y, Qiu Y, Jiang R, Xu M, Zhao L, Chen G, et al. Concomitant high expression of ERa36, EGFR and HER2 is associated with aggressive behaviors of papillary thyroid carcinomas. Sci Rep. 2017;7(1):12279.

52. Rebaï M, Kallel I, Hamza F, Charfeddine S, Kaffel R, Guermazi F, et al. Association of EGFR and HER2 polymorphisms with risk and clinical features of thyroid cancer. Genet Test Mol Biomarkers. 2009;13(6):779-84.

53. Shu C, Yu X, Cheng S, Jing J, Hu C, Pang B. Pristimerin suppresses trophoblast cell epithelial-mesenchymal transition via miR-542-5p/EGFR axis. Drug Des Dev Ther. 2020;14:4659-70.
54. Chia J, Tay F, Bard F. The GaINAc-T activation (GALA) pathway: drivers and markers. PloS ONE. 2019;14(3):e0214118.

\section{Publisher's Note}

Springer Nature remains neutral with regard to jurisdictional claims in published maps and institutional affiliations.
Ready to submit your research? Choose BMC and benefit from:

- fast, convenient online submission

- thorough peer review by experienced researchers in your field

- rapid publication on acceptance

- support for research data, including large and complex data types

- gold Open Access which fosters wider collaboration and increased citations

- maximum visibility for your research: over $100 \mathrm{M}$ website views per year

At BMC, research is always in progress.

Learn more biomedcentral.com/submissions 